e-ISSN: 1984-4255 $\quad$ ARGUMENTOS

D0I: https://doi.org/10.36517/Argumentos.23.3

\title{
O estatuto da música tonal em Susanne Langer
}

\section{The statute of tonal music in Susanne Langer}

\author{
Ivânio Lopes de Azevedo Júnior \\ https://orcid.org/0000-0003-2548-3259 - E-mail: ivanio.azevedo@ufca.edu.br \\ Ilana Viana do Amaral \\ https://orcid.org/0000-0003-4045-0324 - E-mail: ilana.amaral@bol.com.br
}

\begin{abstract}
RESUMO
Este artigo tem como objetivo entender em que termos a música, para Susanne Langer, é interpretada à luz de uma Filosofia das Formas Simbólicas. Esta expressão, por sua vez, é a que designa o programa teórico de seu mestre, Ernst Cassirer. A teoria da arte que Langer propõe, em Filosofia em nova chave e em Sentimento e Forma, se pretende uma continuidade da crítica da cultura empreendida por Cassirer, a qual se fundamenta na ideia de que, uma vez demonstrada a necessidade do simbolismo (função psicológica sem a qual não há cultura), cabe à filosofia compreender e acompanhar o desenvolvimento histórico dos modos de manifestação do Espírito. A música, enquanto a mais abstrata das artes, é um modo particular de simbolismo cujo amadurecimento de sua forma interna desemboca no que chamamos hoje de música tonal. O tonalismo é o estágio em que a música atinge sua maior idade justamente por ter se mostrado capaz de operar a partir de leis próprias, sendo assim, o resultado de um longo processo de constituição da forma musical.
\end{abstract}

Palavras-chave: Susanne Langer. Música. Simbolismo. Forma.

\begin{abstract}
This article aims to understand in terms of music, for Susanne Langer, interpreted in the light of a Symbolic Forms Philosophy. This expression, in turn, is a project or theoretical program of its master, Ernst Cassirer. A theory of art that Langer proposes in Philosophy in the New Key and in Feeling and Form is thought to be a continuity of Cassirer's critique of culture, an idea based on the conception that once the need for symbolism has been demonstrated (function without
\end{abstract}


which there is no culture), it is up to philosophy to understand and follow the historical development of the modes of manifestation of the Spirit. The Music, while the most abstract of the arts, is a particular mode of symbolism, whose maturity is its internal way of transmitting in what we now call tonal music. The tonalism is the stage in which music reaches its older age only because it has been able to operate from the laws of execution, thus being the result of a long process of constitution of the musical form.

Keywords: Susanne Langer. Music. Symbolism. Form.

\section{Introdução}

O propósito central deste artigo é apresentar e analisar a compreensão de Susanne Langer ${ }^{1}$ em torno da natureza da música e da experiência simbólica ${ }^{2}$ que a constitui enquanto tal. Para Langer, a música possui uma história tardia frente às artes como a pintura, a arquitetura e a escultura, pois o amadurecimento de sua forma e de sua capacidade de expressão artística são recentes. Em um primeiro momento, parece haver certa tensão entre a filosofia de matriz kantiana proposta por Langer e uma possível abertura para história. A universalidade e a necessidade do fundamento apriorístico que, para sua interpretação, reside na função simbólica constitutiva do humano, podem vir a sugerir que a dinâmica de constituição da experiência artística seja de uma vez por todas resolvida à revelia das flutuações históricas. Entretanto, esta função simbólica, sem a qual não há relação sujeito-objeto, é a operação formal que possibilita o desenvolvimento histórico das manifestações do espírito em qualquer forma de simbolismo. A cultura é o conjunto de todas expressões simbólicas historicamente manifestas.

Assim como a linguagem, a arte se desenvolveu ao ponto em que hoje se encontra. Ambas possuem uma história e um processo de formação que as conduziram de seus estados mais primitivos às formas mais desenvolvidas. No campo das artes, em especial, cada uma em particular também possui sua construção histórica, suas fases de desenvolvimento e de estagnação. A pintura, a escultura e a arquitetura saíram de sua fase pré-artística bem antes da música, isto é, conseguiram alcançar o estágio de expressão de sua forma significativa em uma época anterior. $\mathrm{O}$ que seria dizer que o desenvolvimento das artes não é uniforme e concomitante porque suas especificidades provocam diferenças em seus processos de constituição.

Pois bem, analisaremos este aspecto do pensamento de Langer que, a nosso ver, revela algo importante de sua filosofia da música, a saber: que o tonalismo, um dos vários sistemas musicais existentes, parece ser a expressão mais acabada da música, além de atuar como uma espécie de background necessário da experiência musical. O compositor exerce sua liberdade

\footnotetext{
1 Susanne Langer (1895-1985), filósofa norte americana que atravessou quase todo o século XX, é herdeira direta de Ernst Cassirer (1874-1945), trazendo em sua compreensão da música o mesmo espírito do sistema teórico de seu mestre o qual se conhece por Filosofia das Formas Simbólicas. O fundamento deste programa filosófico no qual Langer está inserida assume que o ser humano é um animal simbólico, sendo o símbolo, por sua vez, a nova chave à luz da qual a filosofia deve ser articulada enquanto uma crítica da cultura, ampliando assim o projeto de Kant que teria se limitado, segundo Cassirer, a uma crítica da razão.

2 O simbolismo é uma operação constitutiva da psicologia humana, é condição de possibilidade da experiência, portanto, válida a priori. É o seu fundamento antropológico que, enquanto energia vital, garante ao homem a pluralidade de suas manifestações culturais, bem como a possibilidade de sua unidade sistemática. A capacidade de simbolizar de diferentes modos, além de ampliar o escopo da experiência possível frente à crítica da razão promovida por Kant, é assumida como o traço que distingue os homens dos demais seres naturais. Cassirer tomou como uma de suas tarefas, principalmente ao longo da década de 1920, compreender em profundidade as diferenças entre as diversas formas de constituição da experiência, ou seja, seu trabalho na maturidade foi entender, por dentro, o funcionamento das formas simbólicas que, historicamente, iam se ampliando e se aprofundando. No que toca à linguagem, ao mito e ao conhecimento Cassirer deixa uma contribuição significativa, o que não ocorre na mesma proporção com outras formas simbólicas: a arte, por exemplo. Langer irá dar prosseguimento ao projeto de Cassirer propondo uma teoria da arte que à luz da música, a mais abstrata dentre as demais artes, expressaria as suas determinações internas.
} 
criativa sobre uma matriz tonal subjacente que corresponde a algo como uma estrutura espiritual constituída. A forma lógica necessária à música, apontada por Langer em Filosofia em nova chave, aparenta não se limitar às meras analogias entre estruturas musicais e estruturas mentais, pois em Sentimento e forma, obra que pretende ser uma continuidade da primeira, Langer radicaliza essa compreensão. Não é mais suficiente apenas defender que a música é a expressão lógica dos sentimentos, mas agora é a própria música tonal que é a condição mesma de expressão das formas universais da vida interior apresentadas na primeira obra. A tese de Langer a ser aqui entendida é: "a música é um análogo tonal da vida emotiva." (LANGER, 2011, p. 28).

Para tanto, faz-se necessário compreendermos três aspectos de sua interpretação filosófica sobre a música: i) do ponto de vista histórico, a música demorou a se constituir como arte, enquanto possibilidade de expressão da sua forma significativa, porque suas formas expressivas são menos intuitivas e seu material sensível, o som, só chegou ao grau de maturidade espiritual, para a comunicação simbólica, tardiamente; ii) a música é uma "arte do tempo." (LANGER, 2011 , p. 128). O sentido da noção de "tempo" não se confunde, aqui, com a grandeza física, natural e de caráter unidirecional. A música ao expressar as formas universais da vida interior simula um tempo virtual, particular à experiência artística, no qual ocorre a dinâmica das formas. Assim, é fundamental entender em que consiste o tempo na música, pois este é seu aspecto primeiro; iii) A dinâmica das formas universais expressas pela música no tempo virtual, por ela mesma criado, encontrou nos termos do sistema tonal as condições necessárias de sua manifestação. O conteúdo simbólico da música, que pressupõem o material sensível e as formas universais elaboradas na experiência, pelo espírito, encontrou no tonalismo o construto racional adequado tanto para sua expressão quanto para a compreensão de sua forma lógica.

\section{Música, história e forma simbólica}

A música demorou a se constituir enquanto expressão acabada do simbolismo artístico por trabalhar com formas internas do sentimento que são bem menos intuitivas frente às formas externas tais como as linhas, as cores e o espaço presentes nas artes visuais, por exemplo. Estes elementos encontrados na natureza, assim como os sons, são a matéria bruta das artes. $O$ espírito, ao longo dos séculos, vai racionalizando e controlando o uso desses materiais ao ponto de construir formas primitivas, pré-artísticas. Outras formas podem ser facilmente encontradas na natureza externa. Um pintor pode abstrair a forma espacial de uma rosa tal como o arquiteto pode elaborar o esboço de uma edificação inspirado nas formas de uma geografia serrana. A natureza acaba por fornecer formas ao artista que vão se constituindo enquanto modelos para experiências estéticas futuras. Por mais que os resultados da experiência estética das artes que pressupõem a visão consigam, simbolicamente, comunicar elementos diferentes em relação à experiência não artística, mantém-se a intima relação entre as formas naturais e as formas artísticas. É bastante intuitiva a proximidade entre uma tela realista, possuidora de elementos de expressão da forma artística, e o objeto retratado.

Em se tratando da música, o mesmo não ocorre em virtude da não aproximação intuitiva entre o som e os sentimentos, ou seja, a natureza não fornece ao músico modelos naturais. As manifestações sonoras mais rudimentares consistem, basicamente, em expressões orgânicas dos corpos ou emissões audíveis e aleatórias da natureza, ao invés de formas musicais acabadas. Entretanto, o ouvido sempre aberto à natureza se apropria simbolicamente dos sons e, por eles inspirados, constroem os intervalos, os ritmos e as melodias até o ponto de se tornarem, por repetição, formas fixas à mente (LANGER, 2004, p. 244-245). Para Langer, então, o 
que ocorre é uma apropriação histórico-intelectual dos sons naturais, por parte do espírito, que, inicialmente, não possuem nenhuma conotação musical, sendo meros elementos pré-artísticos. O sujeito enquanto unidade esquemática transcendental, em atividade sensitiva e intelectual, simboliza os dados da natureza e constrói formas musicais determinadas que expressam "tensão e alívio, progressão, ascensão ou queda, movimento, limite, repouso. É nessa qualidade musical que entram na arte, não na sua qualidade original de signos, auto expressões, símbolos religiosos ou imitação de sons semelhantes ao do papagaio." (LANGER, 2004, p. 245).

Em outras palavras, a passagem do momento pré-musical ao estágio propriamente musical, em que é possível ao espírito a comunicação das formas significativas por meio da composição, é resultante de um longo período de apropriação simbólica e espiritual da matéria sonora encontrada na natureza. As razões para a elaboração de formas tonais mais acabadas podem ser as mais diversas, não necessariamente de ordem artística. Padrões melódicos e intervalos rítmicos, certamente, surgiram casualmente para atender demandas práticas e só depois ganharam sentido artístico.

Langer endossa a hipótese defendida pelo compositor William Wallace, em Threshold of Music (19083 apud LANGER, 2004, p. 249), que dos gregos antigos não estariam aptos a ouvir o que podemos ouvir hoje, isto é, a simples distinção entre dissonância e consonância era irreconhecível até o final da idade média. Tal diferenciação que, atualmente, pode ser realizada por um homem médio, com pouquíssimo treino musical, era completamente destituída de sentido aos mais antigos. Mesmo considerando os enormes avanços que gregos e medievais deram à teoria da música, à compreensão dos fenômenos acústicos e ao que se tornaria mais adiante o tonalismo, eles eram incapazes de discernir gradações e certas sofisticações sonoras que, hodiernamente, são facilmente apreensíveis e inteligíveis.

Langer tenta explicar o limite de compreensão musical dos antigos tanto pela própria relação instrumentalizada (técnica) que mantinham com a música, uma espécie de treinamento intelectual, bem como pela inexistência de modelos naturais para a música. Diferentemente, os antigos tiveram grande destaque na pintura, na escultura e na arquitetura porque, nestas artes, ocorria o inverso do que encontramos na música. Além de possuírem formas naturais como modelos, a atuação do espírito na experiência estética dessas artes já era suficientemente avançada ao ponto de ser possível, pelo artista, a expressão de suas formas significativas.

$\mathrm{Na}$ ausência de modelos naturais a partir dos quais a música pudesse se constituir, elementos externos e não musicais como o ritmo e a palavra ajudaram-na a formar padrões tonais de natureza rítmica e melódica, os quais possibilitaram o advento de estruturas propriamente musicais. Gritos, passos e batidas de tambor "nos oferecem naturalmente o primeiro arcabouço lógico, a estrutura esquelética da arte embrionária da música." (LANGER, 2004, p. 251). As primeiras exclamações emocionais, ao serem repetidas, vão assumindo formas verbais com entonações e figuras rítmicas definidas, resultando paulatinamente em cantigas ocupacionais e em canções festivas, dando origem à musical vocal ${ }^{4}$.

Essas considerações históricas reforçam a tese de que a música, em sua forma artística amadurecida, é um fenômeno recente. Além de ser também um elemento importante para que se entenda o estatuto do tonalismo na interpretação de Langer, pois ela, seguindo Wallace, parece sugerir que só na época em que o tonalismo está desenvolvido é possível a expressão artística das formas musicais. É como se todo o esforço histórico realizado pelo espírito em

\footnotetext{
3 Wallace, William. The threshold of music: an inquiry into the development of the musical sense. London: Macmillan, 1908.

4 "Os ajustes dos impulsos de fala às exigências da figura tonal rítmica é a fonte natural de todo cantar, o começo da música vocal." (LANGER, 2004, p. 251).
} 
construir formas musicais desembocasse no sistema tonal moderno, tornando-o a forma lógica ideal e acabada para a expressão do simbolismo musical.

Em segundo lugar, é importante que se compreenda qual o sentido essencial da música, distinguindo-o de seus aspectos laterais. Os sons, os tons, as alturas, os padrões rítmicos em si mesmos não são música precisamente. Certamente são elementos presentes na música, mas não o especialmente significativo em termos artísticos. A mesma interpretação ordinária da música como a autoexpressão literal dos sentimentos dos artistas incentivou uma série de pertinentes estudos sobre os aspectos físicos dos sons, as articulações matemáticas da teoria musical, as implicações psicológicas decorrentes da experiência com a música etc. Tudo isso em função da crença de que o seu cerne está em seus aspectos auditivos, notacionais ou somáticos. Tais esforços de pesquisas, apesar de interessantes e relevantes para propósitos outros, não tocam no propriamente artístico da música. Para Langer, a música é essencialmente a ilusão gerada pelos sons ou nos termos de Eduard Hanslick, a essência da música são "as formas sonoras moventes." (HANSLINK, $1896^{5}$ apud LANGER, 2011, p. 114-115).

\begin{abstract}
Mas o que são tais formas? Não são objetos no mundo real, como as formas normalmente reveladas pela luz, porque o som, embora se propague no espaço, e seja variadamente absorvido e refletido, isto é, ecoado pelas superfícies que encontra, não é suficientemente modificado por elas para dar uma impressão de suas formas, como o faz a luz. Coisas dentro de um aposento podem afetar a tonalidade em geral, mas não influenciam as formas tonais especialmente, nem obstruem seus movimentos, porque formas e movimentos estão de igual modo presentes apenas aparentemente; são elementos em uma ilusão puramente auditiva. (HANSLINK, 1896 apud LANGER, 2011, p. 115).
\end{abstract}

O mesmo caráter ilusório das formas se aplica ao movimento. O meio virtual criado pela música no qual as formas significativas se movem e se expressam consiste em seu elemento artístico central. A esfera em que as formas dinamicamente se movimentam não é a experiência real, fenomênica e mensurável pela ciência positiva, mas o âmbito da pura duração. A experiência artístico-estética, em sua duração, não se confunde com o tempo físico unidirecional e divisível em unidades quantificadas ${ }^{6}$. Pelo contrário, o tempo vivido e experimentado é a ilusão primária da música, logo, o tempo musical concebido diferentemente do tempo físico da vida pública destitui de sentido racional qualquer tentativa de fracionar a duração da experiência gerada por esta forma simbólica?

A música, por conseguinte, simula uma ordem temporal em que suas formas se relacionam somente consigo mesmas em um meio forjado. As formas universais do sentimento, conteúdo significativo da música, se articulam no tempo musical e se apresentam basicamente à audição. Na experiência musical, o tempo se torna audível e as formas universais, em movimento, se mostram inteligíveis. Em resumo, o espírito, com seu poder simbólico, constrói uma matriz musical de significado à luz da qual os sons naturais são elaborados de tal maneira que o tempo virtual, requalificado, passa a ser o locus no qual as formas universais da vida interior se manifestam ao sentido auditivo e à intelecção. É desse modo que a música comunica algo acerca dos sentimentos, da nossa vida interior. A expressão literal e somática dos sentimentos dá lugar à expressão lógica de suas formas ideais que se apresentam enquanto um construto simbólico de grande força comunicativa.

\footnotetext{
${ }^{5}$ HANSLICK, Eduard. Vom musikalisch-schönen: ein beitrag zur revision der ästhetik der tonkunst. Leipzig: JA Barth, 1885.

6 "O tempo virtual está tão separado da sequência de acontecimentos reais quanto o espaço virtual está do espaço real." (HANSLINK, 1896 apud LANGER, 2011, p. 116).

7 ??????????
} 


\section{O tonalismo e a forma musical constituída}

É necessário explicar melhor em que sentido devemos compreender o movimento das formas sonoras no tempo virtual e sua correlação com a vida interior. Para tanto, o devido entendimento da matriz musical própria do tonalismo, bem como suas características internas será fundamental. Langer, durante toda sua Filosofia em nova chave (2004) deixou diversas evidências sobre a centralidade do tonalismo, muitas vezes a própria música tonal é concebida enquanto a música como tal. Se notarmos bem, veremos que a interpretação de Langer reúne uma série de aspectos que, quando compreendidos no todo, sugere uma estreita aproximação entre uma concepção sistemática e a tonal da música.

Eis alguns aspectos de sua interpretação que devem ser entendidos de maneira articulada: a) a música como forma de simbolismo comunica um conteúdo artístico e, por mais que funcione diferentemente da linguagem, precisa se apresentar de modo inteligível, sob pena de cair no âmbito do nonsense, como defendiam os empiristas lógicos (LANGER, 2004, p. 92); b) o conteúdo significativo da música se refere aos sentimentos humanos sem que sejam com eles confundidos. Diferentemente do que tradicionalmente se defendeu, a música é a expressão lógica das formas universais do sentimento e não sua expressão somática, ou seja, o conteúdo artístico da música se situa em uma esfera objetiva e virtual na qual as formas universais se articulam mediante um movimento ilusório para uma apresentação não literal de seus significados; c) é condição ineliminável do simbolismo musical que haja uma forma lógica comum entre a música e os sentimentos sobre os quais ela versa; d) a música se expressa na forma da composição como um todo significativo a partir de estruturas musicais articuladas às quais mantêm semelhança com nossos estados afetivos. O movimento das formas no tempo virtual da música se relaciona diretamente com o ânimo na experiência com a música. Esta, dentre outras coisas, consiste basicamente nessa vivência estética que se assenta na correlação entre estruturas sonoras definidas e estados da alma; e) as estruturas musicais acabadas e adequadas à expressão lógica e significativa de seus conteúdos são resultados de um longo processo histórico. O que significa dizer que a matriz musical de significação foi, enquanto um sistema articulado, construída e não dada a priori.

Sendo assim, retornemos à tese de Langer: "A música é um análogo tonal da vida emotiva". Vejamos duas definições de tonalidade e sistema tonal, respectivamente:

Tonalidade para Schoenberg não é meramente uma coleção de notas, mas sim um tipo de centricidade. Todas as notas de uma coleção-tonal são relacionadas a um centro tonal único, cada qual de uma maneira específica. A função de uma única nota é simbolizada pelo grau da escala que ela representa, a de um acorde depende da sua fundamental, que por sua vez, é um grau escalar sobre o qual o acorde é construído. Tonalidade, portanto, é um conjunto de funções dos graus escalares. (CARPENTER,1983, p. 16-17).

A seguinte:

A base da construção perceptiva do sistema tonal é a dicotomia tensão / relaxamento, ou seja, expectativa e preenchimento (ou violação) da expectativa, sendo que intervalos consonantes dão maior sensação de relaxamento - devido à sua estabilidade - e intervalos dissonantes dão maior sensação de tensão (instabilidade). A partir dessa relação entre tensão e relaxamento, temos o conceito de tonalidade, que é uma noção que está fortemente ligada às escalas do sistema tonal, por se tratar da série de relações hierárquicas entre as notas, em que uma em particular, a chamada tônica, é central. Partindo da polaridade de base da constituição da tonalidade, a tônica de uma escala é a nota de relaxamento, enquanto todas as outras notas se relacionam a ela de acordo com seu grau de tensão. (SANTANA, 2010, p. 21-22). 
À primeira vista a tese de Langer indica a compatibilidade lógica entre a vida emotiva e a música tonal. Não foi o suficiente para ela defender somente a analogia entre a música em geral e a vida emotiva, pois ela escolheu particularmente o sistema tonal, fazendo com que sua interpretação da experiência musical, assim como a da própria música, mantivesse uma aproximação necessária com o tonalismo. Vale lembrar que nem toda música é tonal, os princípios e leis do tonalismo não são absolutos e no século XX, principalmente, encontram-se diversos sistemas musicais de composição, alguns deles avessos à "prisão tonal". Antes mesmo do advento do tonalismo enquanto um sistema acabado, constituído de leis próprias, estruturas musicais definidas, unidades intervalares estabelecidas etc., a música era concebida a partir de outras matrizes. As composições baseadas em contrapontos eram muito mais comuns do que composições construídas sobre relações harmônicas funcionais e melodias derivadas das progressões de acordes que estão em função da força de atração da tônica.

Sobre este aspecto da interpretação de Langer, que reivindica a centralidade do sistema tonal, apresentamos três razões que explicam tal escolha. A primeira tomamos quase como uma consequência necessária de sua compreensão geral da experiência musical. A música é a expressão lógica das formas gerais do sentimento, tem como condição sine qua non uma forma lógica que compatibilize o arcabouço musical e os estados emotivos (subjetivos), a composição é a unidade de significação que comunica no movimento do tempo virtual as formas universais, a música só se expressa enquanto um todo não fragmentado. Estas exigências são plenamente atendidas quando se toma o tonalismo como sendo a matriz de significação musical.

Como vimos na citação acima, o sistema tonal é fundamentado na analogia entre dois estados anímicos: tensão (preparação) e relaxamento (resolução). Isso significa que todo o movimento musical interno e inerente ao sistema (as progressões harmônicas, as melodias, as improvisações e, principalmente, as regras de composição) já tem sua base estabelecida em duas sensações primárias. É importante enfatizar que as palavras tensão e relaxamento não são usadas, no sistema tonal, como meras metáforas ou simples analogias. Trata-se de dois termos que estão absolutamente internalizados no jargão da música e que mantêm uma íntima relação com os sentidos das palavras consonância e dissonância, isto é, o sistema tonal é realmente compreendido à luz da relação tensão/relaxamento. As funções tônica (grau I - resolução) e dominante (grau V-preparação) ${ }^{8}$ da tonalidade se apresentam como estruturas intervalares de acordes que, no contexto de uma progressão harmônica do sistema tonal, expressam o substrato desta matriz musical, o acorde dominante provoca a sensação de tensão e instabilidade, exigindo o retorno ao momento agradável e relaxante provocado pelo acorde tônico. A música, em termos tonais, é comumente compreendida a partir desta dinâmica, assim como todas as suas variações podem ser lidas em termos de aproximação e distanciamento da tônica.

A outra razão pode ser inferida dos comentários de Langer sobre a história da música. Lembremos que sua compreensão do desenvolvimento musical é de caráter progressivo, ou seja, a música vai evoluindo de suas formas pré-musicais até suas formas musicais. Geralmente para atender necessidades práticas, as manifestações sonoras mais primitivas, ganham, por uma série histórica de repetições, o status de forma artística. As estruturas sonoras que antes expressavam o somático passam, ao longo dos séculos, a comunicar significados universais. $O$ sistema tonal é, sob essa perspectiva histórica e desenvolvimentista, o ponto máximo da música ocidental. Muitas das dificuldades de execução e de compreensão musicais resultantes do

\footnotetext{
${ }^{8}$ Apesar das funções de tônica e de dominante estarem presentes em outros acordes da tonalidade, os acordes I e V são seus "lugares originários".
} 
não temperamento das escalas e da ausência de unidades intervalares mínimas, tais quais os semitons, são superadas com o sistema tonal. Este se torna a expressão madura do processo de racionalização da música, pois com ele é efetivamente possível encontrar e indicar no interior da composição a correlação entre sons e sentimentos, entre a música e a vida interior ${ }^{9}$.

O processo de racionalização da música é um pressuposto na interpretação ${ }^{10}$ de Langer, além de ser bastante compatível com ideia de que o simbolismo musical, por ser uma forma de conhecimento do mundo, gera ganho epistêmico porque comunica algo sobre o real. $\mathrm{O}$ conjunto de regras que compõem o sistema tonal, juntamente com todas as suas implicações para a composição e à análise musical, consiste na saída do simbolismo de Langer para mostrar, na prática, a compatibilidade entre estruturas musicais acabadas e a comunicação de conteúdos emotivos.

A terceira razão que explica o estatuto do sistema tonal na interpretação de Langer em torno da experiência pode ser encontrada na posição dela em defesa do sistema de análise musical de Schenker: "A única teoria artisticamente válida e valiosa que eu conheço, baseada primordialmente na natureza composta da tonalidade, é a obra de Heinrich Schenker" (LANGER, 2011, p.112). Nas primeiras décadas do século XX, Schenker atuou em um profícuo debate sobre a natureza da música, o gênio musical, os métodos de análise, dentre outros temas. Em um contexto em que o tonalismo estava sendo posto em xeque por músicos como Shoenberg, $\mathrm{H}$. Schenker ${ }^{11}$ assume a defesa da tonalidade e desenvolve um método de análise que, em última instância, pretende demonstrar que as peças musicais tonais podem ser reduzidas a uma estrutura fundamental (Ursatz) ${ }^{12}$. Sua defesa do sistema tonal foi propositiva, inovadora e bastante pretensiosa, como constata Lacerda (1997):

Sua ideia, expressa sem nenhuma modéstia da introdução do livro, era acrescentar ao estudo do contraponto estrito segundo Fux e ele próprio, e ao estudo do baixo-cifrado segundo Johhan Sebastian e Carl Phillip Emanuel Bach, um estudo definitivo sobre a coerência orgânica do trabalho composicional dos grandes mestres. (LACERDA, 1997, p. 1).

Várias das críticas de Schenker aos seus predecessores contemporâneos iam contra o caráter fragmentário e parcial das recorrentes análises musicais. Em seu lugar, ele propunha uma compreensão global da música. Esta parece ser a ideia central que seduziu S. Langer. Deixando de lado as particularidades desse debate específico e a avaliação sobre a eficácia da análise schenkeriana, importa compreender como a ideia de que a música é uma totalidade orgânica possuidora de uma estrutura fundamental influencia a interpretação de Langer.

A obra de Schenker dá a Langer, nos termos técnicos da análise musical, a explicação em detalhe do processo de composição e a defesa de que a peça composicional é um todo orgânico que pode ser explicitado em seus elementos mais fundamentais. Essas contribuições se

\footnotetext{
9 Lembramos que no debate sobre a história da música e a busca pela compreensão pelo advento do sentido musical, Langer assumiu partido de Willian Wallace, defensor da ideia de que a formas musicais (tonais) são bem tardias, teriam surgido séculos depois da idade média. Uma afirmação de Langer é bem clara na defesa de Wallace: "No entanto, é deveras notável que, embora existisse o órgão durante toda a idade média, ninguém descobrisse as possibilidades de combinações tonais simultâneas; e também que o grande período clássico da música ocorra séculos mais tarde do que outras artes - drama, escultura ou pintura. Se rejeitarmos a hipótese de Wallace, de que o sentido musical só evoluiu com um recente desenvolvimento neurológico, assumimos o encargo de apresentar uma explicação melhor." (LANGER, 2004, p. 250).

${ }^{10}$ Por mais que não encontremos em Langer uma referência aos estudos de Max Weber sobre a racionalização da música, seu modo de conceber a música tonal, baseada no temperamento, como estágio avançado de sua forma artística, é bastante compatível com a reflexão weberiana.

11 "Schenker, que considera (aliás, com boas razões) ter penetrado os segredos da escrita tonal, se dá como dever defendê-la num momento em que seus contemporâneos vienenses, Schöenberg em particular, ameaçam a tonalidade." (N. MEEÙS, 1993, p. 5).

12 Para mais informações sobre o debate entre Schenker e Shoenberg, confira breve resenha das contribuições de Schenker e Shoenberg para a análise musical de Marcos Branda Lacerda (1997).
} 
tornam, para Langer, a autorização teórico-musical de sua filosofia da música, em especial, de sua interpretação da experiência musical, principalmente, quando do momento da composição. Schenker acaba por dotar de sentido empírico e analítico a teoria de Langer. O início do processo criativo se dá na mais absoluta solidão do compositor, em um momento em que a mente criadora reconhece, subitamente, a forma total da composição ${ }^{13}$, uma espécie de estágio embrionário da música que interferirá de maneira dominante em todo o restante da obra. É quando várias possibilidades estarão em aberto diante do compositor, mas sua intenção geral já está definida ${ }^{14}$, é o momento em que a ideia simbólica, já estabelecida, torna-se impessoal e independente de seu criador. Fazendo uso dos mais diversos princípios de articulação presentes na música, o artista compõe as demais partes da obra sob a influência da forma total. A essência de toda música ${ }^{15}$ está em sua capacidade de colocar em movimento as formas universais no tempo virtual, criando a ilusão de um todo orgânico.

A grande tarefa da música é organizar nossa concepção do sentimento em mais do que simplesmente uma consciência ocasional de tempestade emocional, isto é, dar-nos uma introvisão no que pode ser verdadeiramente chamado de vida do sentimento, ou unidade subjetiva da experiência; e ela faz isso pelo mesmo princípio que organiza a existência física num projeto biológico - o ritmo. (LANGER, 2011, p. 133).

No capítulo VIII, de Sentimento e Forma, Langer faz uma extensa digressão sobre a natureza do ritmo tanto na música como no mundo vivo, construindo uma analogia entre o musical e o orgânico que se ampara no que ela designa por princípio da continuidade rítmica o qual é base da vida e da música. Nossa mente, nossa vida interior assim como todas as transformações perceptivas e simbólicas estão submetidas ao império do ritmo. Na música, muito mais do que sinônimo de divisão igual de tempo, o ritmo é "o levantamento de novas tensões através da resolução das tensões anteriores." (LANGER, 2011, p. 133).

Segundo Langer, a forma total da peça, o embrião da música, traz consigo seu ritmo básico que é exatamente o elemento que impõe à composição sua unidade orgânica e seu sentimento total. A análise schenkeriana, portanto, fornece o instrumental para que se entenda, em termos de análise musical, em que sentido a música é um todo orgânico cujo movimento rítmico imanente é expressão mesma de sua vitalidade dinâmica, que consiste no perpétuo devir entre tensão e relaxamento, entre preparação e resolução. Nicolas Meeùs afirma: “O princípio fundamental da teoria schenkeriana é o da prolongação: a obra tonal é essencialmente uma prolongação do acorde de tônica, quer dizer uma inscrição deste acorde na duração" (MEEÙS, 1993, p.7). Se exercitarmos um pouco da análise de Schenker, veremos que todo o seu projeto se baseia na dialética harmonia/contraponto donde se explicam as estruturas fundamentais tanto da harmonia quanto da melodia.

Para Schenker, um dado acorde inicial de uma obra musical é prolongado por toda a composição mediante a aplicação de notas de passagem que são escolhidas nas formas do contraponto. A condução dessas vozes gera novos acordes que, por sua vez, provocam novos contrapontos e assim sucessivamente, isto é, acordes provocam a condução de vozes e a recí-

\footnotetext{
13 "Ele reconhece como forma fundamental da peça; e, daí em diante, sua mente não está mais livre para errar irresponsavelmente de tema em tema, clave e clave, e modo a modo. Essa forma é a composição que ele se sente chamado a desenvolver." (LANGER, 2011, p. 128).

14 "Uma vez reconhecida a forma dominante, a obra é algo como o melhor dos mundos possíveis de Leibniz - a melhor escolha, segundo seu criador, dentre muitos elementos possíveis, cada um dos quais em uma estrutura orgânica, requer tanta desobstrução, preparação e auxilio contextual de outros fatores que, mesmo a ação de um pequeno detalhe, pode comprometê-lo a uma decisão séria. Se ele for competente em sua arte, sua mente está treinada e predisposta a ver cada opção em relação às outras e ao o todo." (Ibidem, p.129)

${ }^{15}$ Inclusive a música atonal (Ibidem, p. 133).
} 
proca é verdadeira. Em outras palavras, a harmonia gera o contraponto e o contraponto gera a harmonia. A análise schenkeriana opera com o intuito de explicitar essa dinâmica essencial que consiste na estrutura fundamental da composição. Do ponto de vista da harmonia, essa estrutura se evidencia quando vemos que, nas composições, o acorde tônico inicial está ligado ao acorde tônico final que por meio de notas de ornamento que, seguindo o fenômeno contrapontístico, formam o acorde de função diferente, o dominante. Eis a estrutura harmônica originária que Schenker chama de arpegiação do baixo. Na melodia, a lógica permanece a mesma, é o que ele designa por Urlinie (linha fundamental): "Antes da chegada à tônica, o encontro da penúltima nota da descida melódica com o $\mathrm{V}$ grau da harmonia forma o acorde de dominante para a cadência perfeita final." (MEEÙS, 1993, p. 7).

O movimento recíproco de retroalimentação da harmonia no contraponto reproduz a estrutura fundamental I - V - I, tônico - dominante - tônico, criando assim uma espécie de "redução ontológica da música". É válido lembrar que essa estrutura fundamental revelada pela análise schenkeriana não se confunde com a forma total originária das composições particulares. A mente do compositor, no momento inicial de sua criação artística, é tomada pela estrutura originária da composição individual que ela elabora e do tema proposto que ainda será terminado. Na maioria dos casos, o compositor não possui consciência de que sua obra particular traz em si uma estrutura fundamental geral que subjaz tanto a harmonia como a melodia de sua composição.

Schenker termina por fornecer à filosofia de Langer uma imagem do todo orgânico. $O$ movimento rítmico e inexorável das notas da harmonia e da melodia que constituem cada composição como um organismo vivo possuidor de uma dinâmica interna, nos termos da análise schenkeriana, é a ideia que seduziu S. Langer: "A essência de toda composição - tonal ou atonal, vocal ou instrumental, mesmo puramente percussiva, se se quiser - é a semelhança de movimento orgânico, a ilusão de um todo indivisível." (LANGER, 2011, p. 133). O nexo entre o tonalismo e o simbolismo musical, precisamente este que Langer encontra na teoria de Schenker, é o que concede unidade apresentativa à forma musical. Esta é a peculiaridade do simbolismo em sua forma artística, na qual se encontra sua especificidade e legitimidade próprias. O específico do simbolismo musical em sua versão tonal está, por fim, no modo de apresentação de uma vida interior em movimento que, mesmo escapando à figuração simbólica e representativa da linguagem, encontra um lugar de expressão em sua forma artística constituída: o tonalismo.

\section{Referências}

BELL, C. Art. 1914. London: Chatto and Windus, 1924.

CARPENTER, P. “Grundgestalt” as tonal function. Music Theory Spectrum, p. 15-38, 1983.

CASSIRER, E. A Filosofia das formas simbólicas. São Paulo: Martins Fontes, 2001.

CASSIRER, E. Ensaio sobre o homem: introdução a uma filosofia da cultura humana. São Paulo: Martins Fontes, 1994.

HANSLICK, E. Vom musikalisch-schönen: ein beitrag zur revision der ästhetik der tonkunst. Leipzig: JA Barth, 1885.

LACERDA, M. B. Breve resenha das contribuições de Schenker e Schoenberg para a análise musical. Revista eletrônica de musicologia. Curitiba, v. 2, n. 1, out.1997. Disponível em: http://www. rem.ufpr.br/_REM/REMv2.1/vol2.1/BreveResenha/Breve Resenha.html. Acesso em: 30 jul. 2019. 
LANGER, S. Filosofia em nova chave. São Paulo: Perspectiva, 1971.

LANGER, S. Filosofia em nova chave. São Paulo: Perspectiva, 2004.

LANGER, S. Philosophy in a new key. The New American Library, 1954.

LANGER, S. Sentimento e Forma. São Paulo: Perspectiva, 2011.

MEEÙS, H. Schenker: une introduction. Liège: Mardaga, 1993.

SANTANA, B. P. Os padrões que ouvimos: uma introdução à interface música-linguagem. 2010. Trabalho de Conclusão de Curso (Graduação em Letras), Universidade Federal do Paraná, Curitiba, 2010.

WALLACE, W. The threshold of music: an inquiry into the development of the musical sense. London: Macmillan, 1908.

\section{Sobre os autores}

\section{Ivânio Lopes de Azevedo Júnior}

Doutor em Educação, professor de Filosofia e Música da UFCA. Email: ivanio.azevedo@ufca.edu.br

Ilana Viana do Amaral

Doutora em Filosofia, professora da UECE.

Email: ilana.amaral@bol.com.br

Recebido em: $1^{\circ} . / 10 / 2019$

Aprovado em: 3/12/2019 